\title{
Inspiratory muscle force in normal subjects and patients with interstitial lung disease
}

\author{
ANDRÉ DE TROYER AND JEAN-CLAUDE YERNAULT \\ From the Chest Service, Erasme University Hospital, Brussels School of Medicine, Brussels, Belgium
}

\begin{abstract}
Measurements of the lowest mouth pressures developed during maximum static inspiratory efforts are related to the recoil force of the lung and occasionally are influenced by 0 glottic closure. The measurement of minimal pleural pressures $(\mathrm{P} \mathrm{pl} \mathrm{min})$ over the entire range o응 inspiratory capacity eliminates both problems and, in addition, provides a good estimate of the subject's cooperation. Using this technique, we have investigated the inspiratory muscle force in 120 T

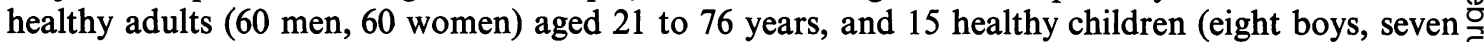
girls)aged 7 to 13 years. Twelve patients with interstitial lung disease were studied for comparison. In the healthy adults, at any fixed (fractional) lung volume, $\mathrm{P}$ pl min increased, that is, became less negative with advancing age, both in males and females (all $\mathrm{r}>0.56, \mathrm{p}<0.001)$. This pattern was not modified ${ }_{\infty}$ after correction of the data for the static recoil pressure of the chest wall, indicating that the inspiratory muscle force actually decreases with age. In any age group, and after correction of lung volume for the difference in stature, the P pl min values in women were between 80 and $90 \%$ of the values found in men; moreover the children generated pressures that were as low as those developed by the younger adults. This is probably because women and children have a smaller thorax than men and $\frac{\circ}{\mathbb{D}}$ are therefore able to generate low pressures despite weaker muscles. When the reduction in lung volume was taken into account, the relationship between lung volume and $\mathrm{P}$ pl min was normal in the patients with interstitial lung disease. These patients showed a close relationship between the degree of lung volume restriction and the increase of the static recoil pressure of the lung at full inflation, suggesting that their thorax is normally compliant. It appears therefore that these patients have normal inspiratory muscle force, at least when they are not in an advanced stage of the disease.
\end{abstract}

Respiratory muscle weakness is a recognised consequence of myopathic diseases. In the last two decades measurements of maximal static mouth pressures have proved useful in establishing the existence of respiratory muscle involvement in myopathic patients and in quantifying the degree of involvement. Although maximal airway pressures give some idea as to the total effect of the respiratory muscles, glottic closure is a problem that often occurs and gives misleading results, ${ }^{1}$ and the introduction of a small air leak at the mouth does not suppress completely the possibility of developing substantial pressure with the cheeks. A second problem, that may be of importance when dealing with patients who have very reduced or clearly increased transpulmonary pressure as a result of lung disease, arises from the fact that the recoil force of the lung contributes to the maximum

Address for reprint requests: Dr A De Troyer, Chest Service, Erasme University Hospital, 808 Route de Lennick, 1070 Brussels, Belgium. static mouth pressures. For these reasons, evaluation of respiratory muscle force using maximum static airway pressures occasionally will be approximate. Measurement of oesophageal rather than mouth pressures developed during maximum static $\frac{7}{0}$ respiratory efforts, although requiring the patient to swallow a tube, eliminates both problems. Oे

Using this technique, we examined a large group $N$ of healthy adults and children of both sexes, in $\stackrel{\sim}{\mathrm{N}}$ order to establish prediction equations and evaluate $\omega$ the influence of age, sex, and height upon the inspiratory muscle force. We also studied a group $\stackrel{\circ}{\subset}$ of patients with interstitial lung disease to define $\stackrel{\circledast}{\circledast}$ the impact of a large reduction in lung size on the inspiratory muscle force and its relationship with the lung retractive properties.

\section{Principles}

The static mechanical properties of the normal 92 


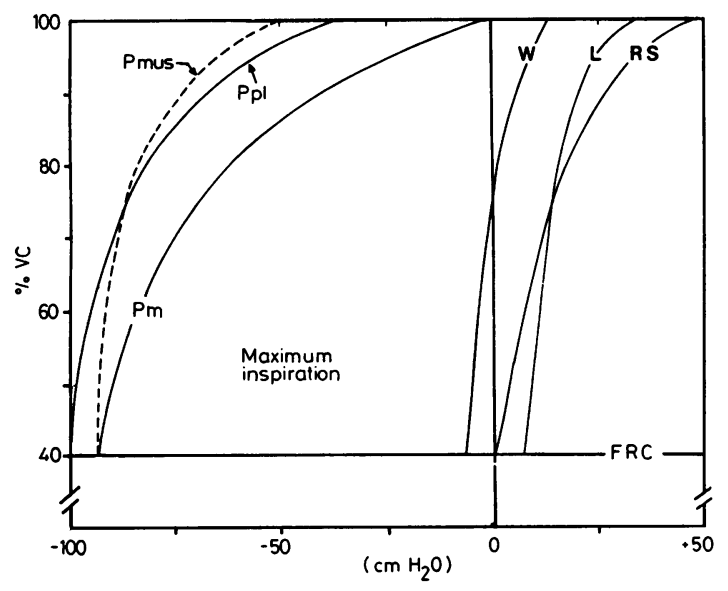

Fig 1 Static pressure-volume relationship of lungs $(L)$, chest wall $(W)$, and total respiratory system $(R S)$ above $F R C$ in a sitting, awake, subject. The solid lines in the left part of the diagram represent the volume-mouth pressure $(\mathrm{Pm})$ and the volume-pleural pressure $(\mathrm{Ppl})$ curves obtained during maximum static inspiratory efforts. The broken line (Pmus) indicates the pressure contributed by the muscles.

respiratory system during voluntary relaxation and maximum inspiratory effort have been well documented. ${ }^{23}$ If the respiratory muscles are completely relaxed against a closed shutter, the pressure measured at the mouth, Pm, at any lung volume is the sum of the static recoil pressures of the lungs (Pst(L)) and of the chest wall (Pst(W)), or

$$
[\mathrm{Pm}=\operatorname{Pst}(\mathrm{L})+\operatorname{Pst}(\mathrm{W})=\text { Pst }(\mathrm{RS})]
$$

where Pst(RS) is the static transrespiratory pressure. Figure 1 represents the normal pressure-volume behaviour of lungs (L), chest wall (W), and total respiratory system (RS) in a sitting awake subject. In this diagram, and in the following equations, all pressures are expressed relative to the pressure at the body surface, $\mathrm{Pb}$.

As the lungs and chest wall are in series with one another, the total pressure required to displace the respiratory system is the sum of the pressures acting across the lungs and chest wall. So that, during voluntary maximum inspiratory efforts exerted against a closed shutter (there is no gas flow and thus, no change in lung volume), the change in mouth pressure is equal to the transrespiratory pressure of the relaxed system plus the net pressure exerted by the contraction of the respiratory muscles (P mus):

$[\mathbf{P m}=\mathbf{P s t}(\mathbf{R S})+\mathbf{P m u s}=\mathbf{P s t}(\mathrm{L})+\mathbf{P s t}(\mathrm{W})+$ Pmus $]$

During the same maximum inspiratory effort, the change in pleural pressure $(\mathrm{Ppl})$ relative to $\mathrm{Pb}$ will be:

$$
[\mathrm{Ppl}(-\mathrm{Pb})=\operatorname{Pst}(\mathrm{W})+\text { Pmus }]
$$

and the difference between Pm and Ppl is the static recoil pressure of the lung, or

$$
[\mathrm{Pm}=\mathrm{Ppl}+\mathrm{Pst}(\mathrm{L})]
$$

In the left part of fig 1 , the solid lines represent the volume-mouth pressure and the volume-pleural pressure relationships of the system during maximum static inspiratory efforts. The horizontal distance between these two curves is the static recoil pressure of the lung, and the horizontal distance between the volume-pleural pressure curve and the volumepressure curve of the relaxed chest wall (W) gives the net pressure exerted by the inspiratory muscles (broken line-Pmus). Thus the minimal (greatest negative) pleural pressure ( $\mathrm{P} \mathrm{pl} \mathrm{min}$ ) developed during a maximum static inspiratory effort will be independent of the static recoil pressure of the lung at the volume at which the manoeuvre is performed, and it will depend only on the net pressure exerted by the contraction of the muscles and on the static recoil pressure of the relaxed chest wall.

It must be emphasised that mouth and pleural pressures during maximal static inspiratory efforts are subatmospheric and thus, negative in sign. In this paper, all the pressures will be expressed with their proper sign-for example, a fall in inspiratory muscle force will be reflected by an increase in $\mathrm{P}$ pl min.

\section{Subjects and methods}

The study was performed on 120 healthy adults (60 men, 60 women), 21 to 76 years of age, 15 healthy children (eight boys, seven girls), 7 to 13 years of age, and 12 patients with diffuse interstitial lung disease.

The healthy subjects were recruited from people working in the hospital or their relatives; all of them were lifelong non-smokers and were free from respiratory or cardiac disease. They were subdivided into 12 groups according to sex and age. The number of individuals in each group, their average age, height, and lung volumes are shown in table 1 . Among the 120 adults, there were about 10 men and 10 women in each decade from 30 to 60 years and in a group of subjects older than 60 years in which the oldest man was 75 years old and the oldest woman 76. Only four of the subjects (all young men) were trained in respiratory manoeuvres, and none was an athlete.

Of the 12 patients with interstitial lung disease 
Table 1 Sex, age, height, and lung volumes (mean $\pm S D$ ) in the 135 normal subjects studied

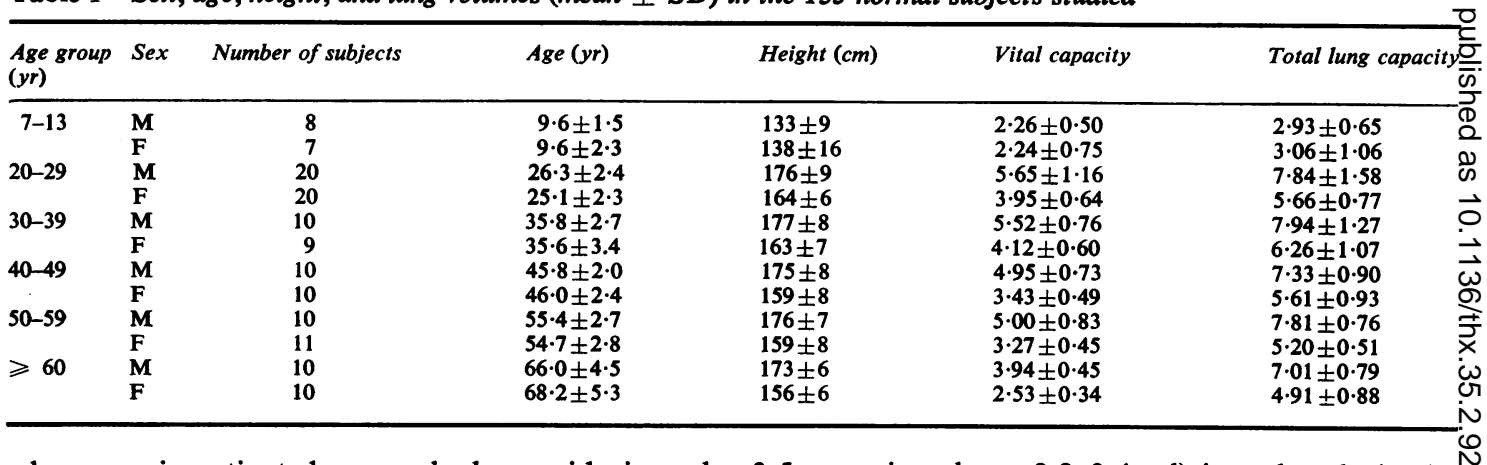

who were investigated, seven had sarcoidosis and extensive pulmonary involvement; two patients had longstanding asbestosis and pulmonary fibrosis but did not show any evidence of pleural involvement on chest radiographs; the three other patients had pulmonary fibrosis caused by scleroderma (two cases) and pigeon breeder's disease (one case). In each case, the diagnosis rested upon clinical, radiological, and histological data. There were seven men and five women, with a mean $( \pm S D)$ age of $47.0 \pm 12.4$ years. The main pulmonary function data are given in table 2. The patients had clear restrictive ventilatory impairment, with VC $62.7 \%$ of predicted, and TLC $75.4 \%$ of predicted. At the time they were investigated, all these patients were in a chronically stable state. They were moderately disabled, and most of them had only mild dyspnoea on exertion. All subjects gave informed consent to the studies.

All the measurements were carried out with the subject in the sitting position. The static lung volumes, including the functional residual capacity (FRC), and maximum expiratory flow-volume curves were obtained in a constant volume plethysmograph. Expiratory pressure-volume (PV) curves of the lung were obtained by a quasi-static method ${ }^{5}{ }^{6}$ with an oesophageal latex balloon (length $10 \mathrm{~cm}$; perimeter

Table 2 Main pulmonary function data in 12 patients with interstitial lung disease

\begin{tabular}{|c|c|c|c|c|c|}
\hline Subjects & $\begin{array}{l}V C \\
(l)\end{array}$ & $\begin{array}{l}F R C \\
(l)\end{array}$ & $\begin{array}{l}T L C \\
(l)\end{array}$ & $\begin{array}{c}F E V_{1 \cdot 0 / V C} \\
(\%)\end{array}$ & $\begin{array}{l}\text { Pst(L) at TLC } \\
\left(\mathrm{cm} \mathrm{H} \mathrm{H}_{2} \mathrm{O}\right)\end{array}$ \\
\hline \multicolumn{6}{|l|}{ Patients } \\
\hline $\begin{array}{l}\text { Mean } \\
\text { SE }\end{array}$ & $\begin{array}{l}2 \cdot 86 \\
0 \cdot 23\end{array}$ & $\begin{array}{l}2 \cdot 97 \\
0 \cdot 28\end{array}$ & $\begin{array}{l}4.79 \\
0.45\end{array}$ & $\begin{array}{r}73 \cdot 0 \\
2 \cdot 8\end{array}$ & $\begin{array}{r}51 \cdot 2 \\
4 \cdot 5\end{array}$ \\
\hline \multicolumn{6}{|l|}{ Predicted } \\
\hline $\begin{array}{l}\text { Mean } \\
\text { SE }\end{array}$ & $\begin{array}{l}4.56 \\
0.30\end{array}$ & $\begin{array}{l}3 \cdot 32 \\
0 \cdot 21\end{array}$ & $\begin{array}{l}6 \cdot 35 \\
0 \cdot 34\end{array}$ & $\geqslant 70$ & $\begin{array}{r}29 \cdot 0 \\
1.0\end{array}$ \\
\hline
\end{tabular}

The predicted values for lung volumes are those of Amrein et al4; predicted values for static recoil pressure of the lung (Pst(L)) are derived from measurements performed in the 120 healthy adults reported in the present study.
$3.5 \mathrm{~cm}$; air volume $0.2-0.4 \mathrm{ml}$ ) introduced via the nose into the oesophagus. A marker was placed on the polyethylene tubing exactly $42 \mathrm{~cm}$ from the $\vec{T}$ balloon tip and balloon adjustment began when $\frac{\mathbb{O}}{\sigma}$ this marker appeared at the external nares. Recording of the curves was preceded by three full inflations to assure a constant volume history. Lung $\vec{\oplus}$ volume was plotted against transpulmonary pressure ${ }^{\circ}$ on a direct-writing $\mathrm{X}-\mathrm{Y}$ recorder. Several $\mathrm{PV} \cdot$ curves were performed in each subject and a line of best fit was drawn by eye through at least three sets of PV data that agreed to $\pm 1 \mathrm{~cm} \mathrm{H}_{2} \mathrm{O}$. The static recoil pressure of the lung (Pst (L)) was measured at various percentages of TLC which was $\odot$ calculated by adding to FRC the mean inspiratory $\overrightarrow{\overrightarrow{0}}$ capacity measured during the X-Y recording of the 3 PV curves. The same technique was used for obtaining expiratory $\mathrm{PV}$ curves in the children of the present study, except for the distance between balloon tip and nares. ${ }^{7}$

Minimal (negative) pleural pressures (P pl min) $\stackrel{\bigotimes}{\times}$ were obtained by repeated measurements at various $\frac{3}{3}$ lung volumes while the subject, seated outside the body plethysmograph, attempted maximum inspira- $O$ tory efforts against a closed shutter. The pressure transducer was calibrated with a mercury mano- $\frac{\text { ? }}{3}$ meter; it was linear to minus $130 \mathrm{~cm} \mathrm{H}_{2} \mathrm{O}$ inspiratory pressure. A conventional mouthpiece and noseclip were used, and pressures sustained for one second $N$ were recorded. At least 15 maximal efforts were recorded on each subject at different lung volumes $\triangle$ between the resting level (FRC) and TLC, and at $\omega$ each level of lung volume the lowest recorded value was used to construct a curve of P pl min against lung $\stackrel{\bullet}{ }$ volume.

A tracing obtained in a 28 -year-old man is shown $\stackrel{\leftrightarrow}{?}$ in fig 2. As illustrated in this graph, $\mathbf{P}$ pl min was lower than transpulmonary pressure at TLC in $\frac{\vec{D}}{\Phi}$ most of the subjects. This could appear somewhat $\stackrel{\square}{\overparen{Q}}$ surprising, since P mouth at TLC must be zero. $\stackrel{\unrhd}{\varrho}$ The difference between P pl min and Pst (L) at TLCO is explained by the way both measurements are 


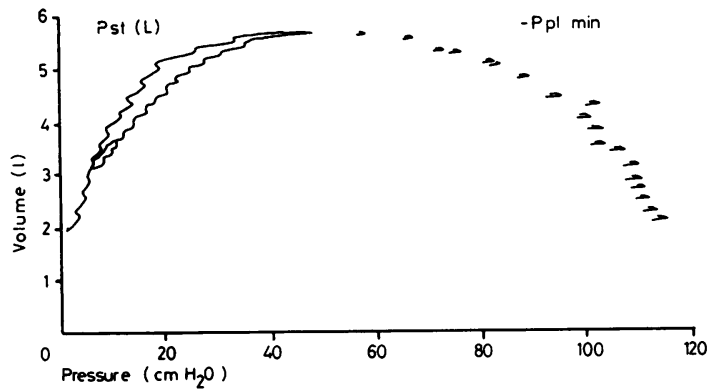

Fig 2 Recordings of lung recoil pressure (Pst $(L))$ (quasi-static method) and of the mirror image of minimal pleural pressures ( $P$ pl min) versus lung volume in a healthy 28-year-old man.

performed: Pst (L) at TLC is that value of transpulmonary pressure sustained for several seconds breath-holding at full inflation, whereas $\mathrm{P} \mathrm{pl} \mathrm{min} \mathrm{is} \mathrm{a}$ peak pressure. Also shown in the figure is the fact that the volume-P pl min diagram was curvilinear in each subject: the shape was close to a parabola with its vertex between 50 and $60 \%$ TLC. To render comparisons between different individuals possible, the volume was expressed as a percentage of TLC.

\section{Results}

\section{NORMAL SUBJECTS}

In no age group and at no given lung volume was there any significant difference in Pst $(\mathrm{L})$ between males and females; therefore no differentiation between men and women was made in the analysis of Pst (L) data. Lung recoil pressures, measured at fixed percentages of TLC, decreased significantly with age. The regression coefficients, constants, correlation coefficients, and standard errors of all lung volumes examined are given in table 3 . Pressure was found to decrease with advancing age, more markedly so at higher lung volumes.

Table 3 Statistical analysis of elastic recoil pressure of the lungs at various levels of total lung capacity versus age in 120 subjects aged 21-76 years

\begin{tabular}{|c|c|c|c|c|}
\hline$y$ & $a$ & $b$ & $S E E$ & $r$ \\
\hline 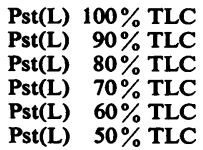 & $\begin{array}{r}41 \cdot 80 \\
20 \cdot 27 \\
15 \cdot 40 \\
12 \cdot 08 \\
9 \cdot 00 \\
6 \cdot 24\end{array}$ & $\begin{array}{l}-0 \cdot 271 \\
-0 \cdot 132 \\
-0 \cdot 115 \\
-0 \cdot 103 \\
-0 \cdot 084 \\
-0 \cdot 064\end{array}$ & $\begin{array}{l}5 \cdot 87 \\
2 \cdot 51 \\
1.99 \\
1 \cdot 72 \\
1 \cdot 57 \\
1 \cdot 46\end{array}$ & $\begin{array}{l}0.59 \\
0.64 \\
0.67 \\
0.68 \\
0.64 \\
0 \cdot 52\end{array}$ \\
\hline
\end{tabular}

$a, b=$ coefficients in regression equations of the type $y=a+b x$, where $y$ is the measurement and $x$ is age in $y r ; r=c o r r e l a t i o n$ coefficient of measured variable versus age; all values are significant at $p<0.001 ; \mathrm{SEE}=$ one standard error of the estimate; Pst(L) is given in $\mathrm{cm} \mathrm{H}_{2} \mathrm{O}$.

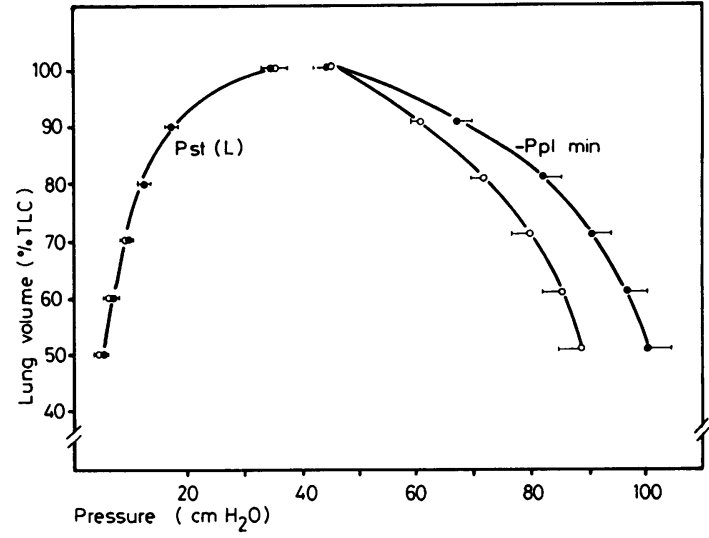

Fig 3 Curves of lung recoil pressure (Pst $(L))$ and of the mirror image of minimal pleural pressure $(P$ pl min) versus lung volume, expressed as a percentage of total lung capacity (TLC), in normal subjects aged 20-29 years. Closed symbols are mean values obtained in 20 men; open symbols are average values obtained in 20 women Bars indicate \pm 1 SEM.

During maximum static inspiratory efforts, women developed on the average pressures that were slightly less negative than those generated by men of equivalent age. For the sake of illustration, the data obtained in the 20-29 yr age groups are shown in fig 3. At any fixed (fractional) lung volume, the minimal (negative) pleural pressure was higher in women than in men, more markedly so at lower than at higher lung volumes. When expressed in that way, there was no difference in P pl min values at TLC between the two sexes. The results obtained after correction of lung volume for the difference in stature (TLC/height ${ }^{3}$ ) between males and females are shown in fig 4. The right part of the diagram presents the PV curves of the lung (solid lines) obtained in the young males (closed circles) and young females (open circles), and the chest-wall PV curves. These latter, indicated as dashed lines, are conjectural, in the sense that we have assumed that men and women of equivalent age have a similar PV relationship of the chest wall. In the left part of the diagram, are shown the volume-P pl min curves obtained in the two groups of subjects (solid lines). The heavy dashed lines are the corresponding volume-P mus relationships, calculated for each group as the horizontal distance between the volume-P pl min and the chest wall PV curves (equation 3). It appears evident from this graph that, when the difference in stature between the two sexes is taken into account, the volume-P mus relationship has a parallel shape in men and in women; at any comparable lung volume, $\mathbf{P}$ mus in 


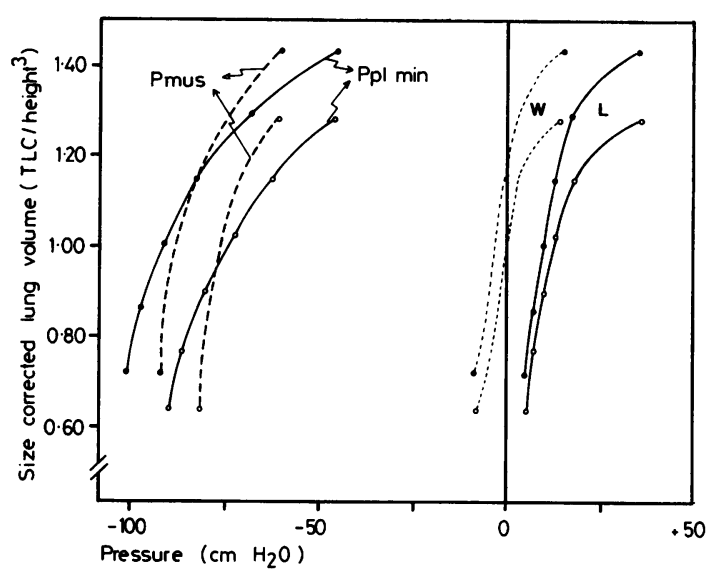

Fig 4 Same data as in fig 3, with lung volume corrected for the difference in stature (TLC/height ${ }^{3}$ ) between men and women. In the right part of the graph, are given the static pressure-volume curves of the lungs (solid lines-L) and of the chest wall (dashed lines-W). The solid lines in the left part of the diagram represent the volume-pleural pressure ( $P$ pl min) curves obtained during maximum static inspiratory efforts. The heavy dashed lines (Pmus) indicate the net pressure exerted by the inspiratory muscles at the different lung volumes. Closed circles are values of young men; open circles are values of young women. See text for further explanation.

young women is $85-90 \%$ of $\mathrm{P}$ mus in young men. The same analysis may be applied to the various age groups of this study: it shows that, in any age group, and after the lung volume has been corrected for the difference in stature, women developed $P$ mus between $80-90 \%$ of the values obtained in men.

Table 4 Statistical analysis of minimal pleural pressure at various levels of total lung capacity versus age in 120 subjects aged 21-76 years

\begin{tabular}{|c|c|c|c|c|}
\hline$y$ & $a$ & $b$ & $S E E$ & $r$ \\
\hline $\begin{array}{l}\text { Males } \\
\text {-P pl min } 100 \% \text { TLC } \\
\text {-P pl min } 90 \% \text { TLC } \\
-P \text { pl min } 80 \% \text { TLC } \\
-P \text { pl min } 70 \% \text { TLC } \\
\text {-P pl min } 60 \% \text { TLC } \\
-P \text { pl min } 50 \% \text { TLC }\end{array}$ & $\begin{array}{r}57 \cdot 20 \\
83 \cdot 32 \\
100 \cdot 56 \\
110 \cdot 28 \\
118 \cdot 32 \\
122 \cdot 21\end{array}$ & $\begin{array}{l}-0.44 \\
-0.59 \\
-0.68 \\
-0.70 \\
-0.74 \\
-0.76\end{array}$ & $\begin{array}{r}8 \cdot 29 \\
10.54 \\
13 \cdot 41 \\
14 \cdot 94 \\
15 \cdot 85 \\
17 \cdot 00\end{array}$ & $\begin{array}{l}0.63 \\
0.65 \\
0.61 \\
0.57 \\
0.58 \\
0.56\end{array}$ \\
\hline $\begin{array}{l}\text { Females } \\
\text {-P pl min } 100 \% \text { TLC } \\
\text {-P pl min } 90 \% \text { TLC } \\
\text {-P pl min } 80 \% \text { TLC } \\
\text {-P pl min } 70 \% \text { TLC } \\
\text {-P pl min } \quad 60 \% \text { TLC } \\
\text {-P pl min } \quad 50 \% \text { TLC }\end{array}$ & $\begin{array}{r}54.06 \\
71 \cdot 03 \\
82 \cdot 69 \\
92 \cdot 17 \\
99 \cdot 90 \\
102 \cdot 77\end{array}$ & $\begin{array}{l}-0.41 \\
-0.46 \\
-0.51 \\
-0.57 \\
-0.64 \\
-0.64\end{array}$ & $\begin{array}{r}7 \cdot 13 \\
9 \cdot 08 \\
10 \cdot 18 \\
11 \cdot 29 \\
12 \cdot 71 \\
13 \cdot 98\end{array}$ & $\begin{array}{l}0 \cdot 68 \\
0 \cdot 64 \\
0 \cdot 63 \\
0 \cdot 64 \\
0 \cdot 63 \\
0 \cdot 60\end{array}$ \\
\hline
\end{tabular}

$a, b=$ coefficients in regression equations of the type $y=a+b x$, where $y$ is the measurement and $x$ is age in $y r ; r=$ correlation coefficient of measured variable versus age; all values are significant at $\mathrm{p}<0.001 ; \mathrm{SEE}=$ one standard error of the estimate; $\mathrm{P} \mathrm{pl} \mathrm{min} \mathrm{is}$ given in $\mathrm{cm} \mathrm{H}_{2} \mathrm{O}$.

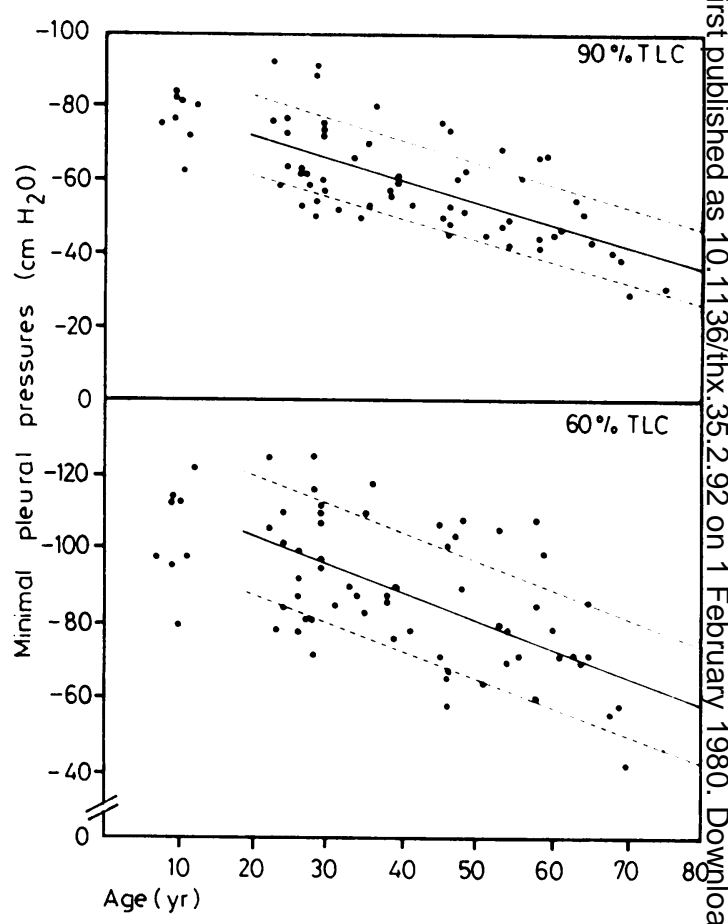

Fig 5 Effect of age on minimal pleural pressure at $90 \%$ 을 (upper panel) and $60 \%$ (lower panel) of TLC in 60 normal men. Full and dashed lines represent regression equations and $\pm 1 S E E$. Also plotted are the data obtained in eight boys, 7-12 years of age.

Because of this difference, $\mathbf{P}$ pl min values were analysed separately for men and women. All minimale pleural pressures correlated positively and significantly with age, both in males and females (table 40 figs 5,6$)$. The increase in $\mathrm{P} \mathrm{pl} \mathrm{min} \mathrm{with} \mathrm{age} \mathrm{was} \mathrm{more}$ marked at lower lung volumes. A parabolio regression line was also determined, but this did not ${ }^{3}$ result in less residual variance than that obtained? from the linear regression. In no age group, in neither sex, and at no given lung volume, were $\mathrm{Ppl} \mathrm{min}$. values correlated with height.

Since the children studied here represented $a^{\circ}$ small sample and also a limited range of age, we $N$ have not attempted to derive prediction equations ${ }^{N}$ and to study the evolution of $\mathbf{P ~ p l ~ m i n ~ d u r i n g ~ g r o w t h ~}$ However it may be seen in figs 5 and 6 that the boyso and girls of our series generated pressures that were as low as those developed by the younger men and? women, respectively.

PATIENTS WITH LUNG VOLUME RESTRICTION

Static lung recoil pressure at full inflation was clearly $\frac{O}{2}$ increased in eight of the 12 patients with interstitialog lung disease. The mean $( \pm$ SEM) observed value for 


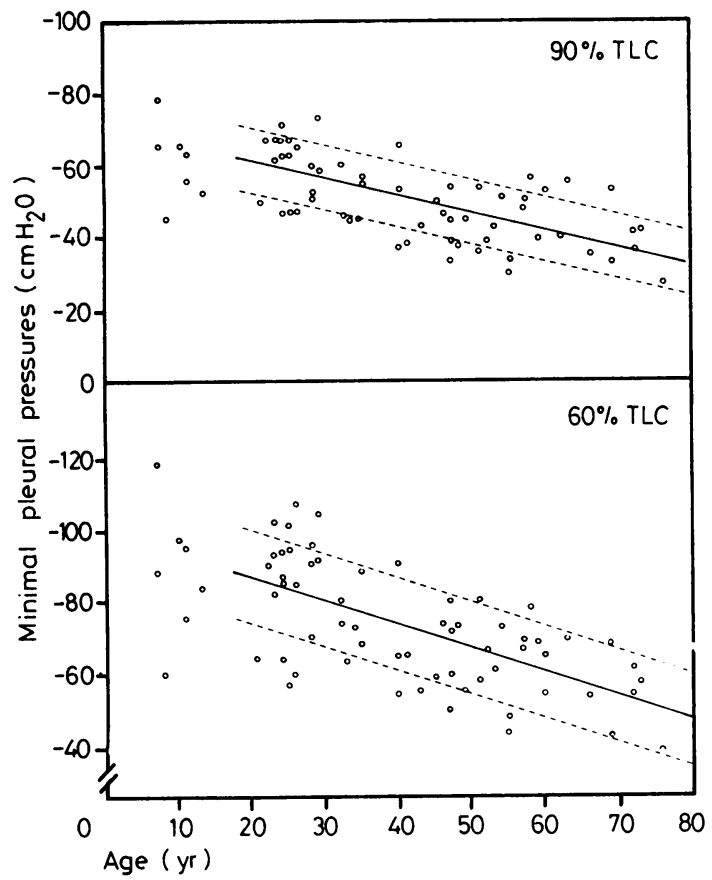

Fig 6 Same data as in fig 6, for 60 normal women, and seven girls aged 7-13years.

the whole group was $51 \cdot 2( \pm 4 \cdot 5) \mathrm{cm} \mathrm{H}_{2} \mathrm{O}$, while the mean $( \pm$ SEM) predicted value was $29.0( \pm 1.0) \mathrm{cm}$ $\mathrm{H}_{2} \mathrm{O}$. A significant relationship was found between TLC and Pst(L) at full inflation (fig 7). Figure 8 shows the mean PV curve of the lung and the mirror image of the mean P pl min-volume diagram for the 12 patients. When the reduction in lung volume was taken into account, the patients, on an average, tended to have normal $\mathbf{P ~ p l ~ m i n ~ v a l u e s ~ a t ~ a n y ~ c o m - ~}$ parable lung volume. This is also illustrated in fig 9 which shows the individual $\mathrm{P} \mathrm{pl} \mathrm{min}$ values at $60 \%$ predicted TLC: most of these values fell within the normal range.

\section{Discussion}

The present study shows that aging is associated with a fall in lung retractive force. This is consistent with most previous work, ${ }^{8-10}$ although Bode et al ${ }^{11}$ did not find any aging effect in females. Some discrepancies also persist concerning the sex differences; in the present series there was no difference in lung elasticity between males and females of equivalent age. Analysis of these differences is beyond the scope of this paper and has been reported in detail elsewhere. ${ }^{12}$

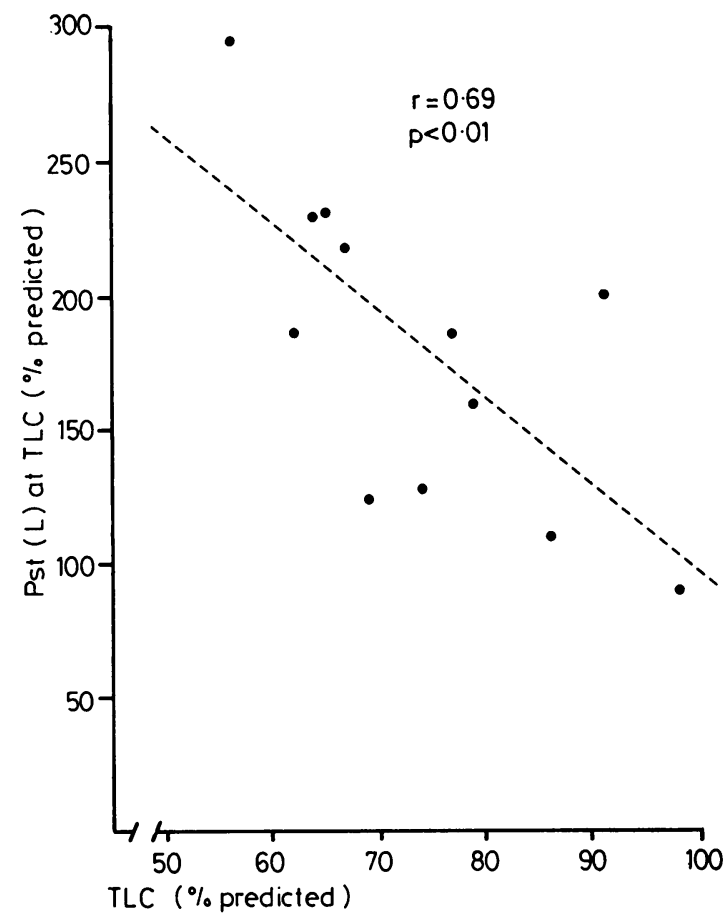

Fig 7 Relationship between total lung capacity (TLC) and static lung recoil pressure $(P s t(L))$ at full inflation in patients with interstitial lung disease. Dashed line is the line of regression.

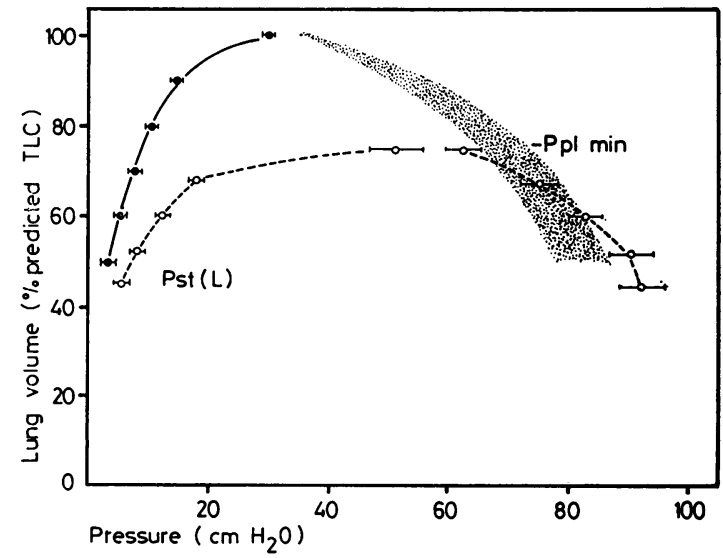

Fig 8 Curves of lung recoil pressure (Pst $(L))$ and of the mirror image of minimal pleural pressure $(P \mathrm{pl}$ min) versus lung volume, expressed as a percentage of predicted $T L C$, in patients with interstitial lung disease (open symbols). Average data for 12 patients; bars indicate $\pm 1 S E M$. Also shown are the predicted (mean $\pm 1 S E$ ) values for Pst (L) (closed symbols) and $P$ pl min (shaded area). 


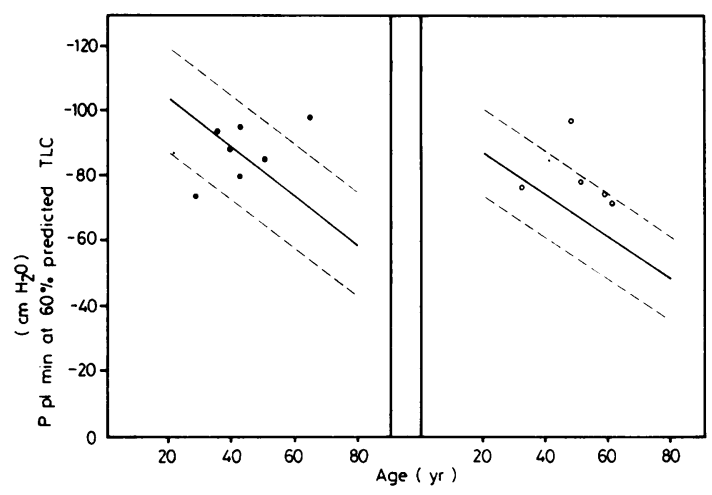

Fig 9 Individual values of minimal pleural pressure (P pl min) at $60 \%$ predicted TLC for 12 patients with interstitial lung disease. Full and dashed lines represent regression equations and \pm 1 SEE obtained in 60 healthy men (left panel) and in 60 healthy women (right panel).

Before considering the causes of the changes we have encountered in inspiratory muscle force, it is pertinent to consider the problems associated with the cooperation of the subjects tested. Development of maximum static respiratory pressures depends not only on the strength and coordination of the respiratory muscles, but also on the motivation and cooperation of the subject. Recording of maximum (airway or pleural) pressures at a single lung volume ${ }^{13} 14$ gives little information on the subject's cooperation, even when the manoeuvres are repeated until two technically satisfactory measurements are obtained. ${ }^{14}$ Recording of repeated measurements of minimal static pleural pressures over the entire range of inspiratory capacity undoubtedly will give a better idea of the subject's cooperation, as the shape of the relationship between lung volume and minimal pressures is known to be close to a parabola with its vertex between 50 and $60 \%$ TLC.

\section{AGE DIFFERENCES}

Several investigators have reported measurements of pressures developed at the mouth during maximal inspiratory efforts on different groups of healthy men and women. Ringqvist ${ }^{13}$ observed that minimal inspiratory mouth pressures near residual volume increased linearly with age, both in males and females. More recently, Black and Hyatt, ${ }^{14}$ though they were unable to demonstrate a significant increase in subjects younger than 55 years, reported that the minimal mouth pressures on inspiration increased with age in subjects older than 55 years. Cook and associates, ${ }^{15}$ using a special apparatus, measured minimal mouth pressures over the range of vital capacity in a large group of healthy people and at any (fractional) lung volume; they observed? less negative values in subjects aged between 47 and $\overline{\bar{n}}$ 64 years than in younger people. However, as stressed previously, measurements of minimum $\varrho$ inspiratory pressures at the mouth are affected by theis lung retractive force (that is known to fall with $\overrightarrow{0}$ advancing age) and also by the static recoil of the chest wall. Although measurements of minimalc pleural pressures are independent of lung elasticity? (equation 3), they are influenced by the elastic $x$ properties of the chest wall. Therefore our observa-c tion that minimal (negative) pleural pressuresiv became less negative with age could reflect changes $N$ in the chest wall pressure-volume curve, rather thano a decrease in the inspiratory muscle force. This possibility seems however very unlikely, though we T) have not measured chest wall PV curves in the을 present study. In the region of spontaneous breathing, there is indeed very little change in Pst (W) with advancing age, ${ }^{8}$ so that the differences in $\mathbf{P}$ muso between older and younger healthy adults wouldo be approximately equal to the one observed in P pl min. We conclude, thus, that the inspiratoryo muscle force actually decreases with advancing age, even though, at high volumes (where inspira tory muscles are at least mechanical advantage)? the tendency of the chest wall to recoil outwarc? seems to diminish with age ${ }^{8}$ and would therefore를 lower $\mathbf{P}$ pl min relatively more in older than in younger people when compared to $\mathrm{P}$ mus.

\section{SEX DIFFERENCES}

The present observations that during maximum inspiratory efforts, females developed pressures that were almost as low as those developed by males of equivalent age, and that young children generate $\overline{5}$ pressures that were similar to those seen in young adults are in agreement with previous studies. ${ }^{13-15}$ In this respect the respiratory muscles are quite different from the other skeletal muscles. It is welp established that females have weaker muscles than males of equivalent age; for example the maximaf voluntary grip strength is much lower in females than in males, and there is practically no overlap. ${ }^{10}$ By contrast the difference in $\mathrm{P} \mathrm{pl} \mathrm{min} \mathrm{between} \mathrm{malesw}$ and females was found to be very small in any age group. This difference between respiratory and othef skeletal muscles probably arises from the fact tha women have a smaller thoracic cage than men, even ${ }^{+}$ after lung volume has been corrected for differences. in stature (fig 4). Although there are obviousp difficulties in applying the Laplace relationship tof the chest because of its complex shape, it may be useful as a first approximation. The relation givere by Laplace equation for a sphere between pressure 
$(P)$, tension $(T)$, and radius $(R)$ is

$$
P=\frac{2 T}{R}
$$

Because females have smaller chests $(R)$ than males, they would be able on inspiration to generate relatively low pressures $(\mathrm{P})$ despite lower muscle strength $(T)$. This is also the most likely explanation for the low pressures developed by the children. For the sake of illustration, we have seen an untrained 3 year old boy (height $=0.86 \mathrm{~m}$; weight $=$ $13 \mathrm{~kg}$ ) who developed inspiratory pressures as low as $-105 \mathrm{~cm} \mathrm{H}_{2} \mathrm{O}$ at FRC, and Agostoni and $\mathrm{Mead}^{2}$ reported that inspiratory pressures of $-70 \mathrm{~cm} \mathrm{H}_{2} \mathrm{O}$ were found in newborn humans.

\section{PATIENTS WITH RESTRICTIVE LUNG DISEASE}

No studies have been reported regarding the effect of interstitial lung disease on the function of the respiratory muscles. Results of the present study indicate that lung volume restriction does not modify the relationship between lung volume and P pl min (fig 8). However, as stressed previously, the $\mathrm{Ppl}$ min values must be corrected for the static recoil of the chest wall to assess the inspiratory muscle force. We are not aware of any measurement of chest wall elasticity in patients with interstitial lung disease, but we believe the present data may be relevant to this point.

Most of our patients had elevated static lung recoil pressure at full inflation. Gibson and Pride ${ }^{17}$ have suggested that the high Pst (L) at full inflation in patients with interstitial lung disease reflected the greater mechanical advantage of the inspiratory muscles in the presence of small lungs. This hypothesis is supported by the finding that a close inverse relationship existed in our patients between the degree of lung volume restriction and the degree of increase in Pst (L) at full inflation. The smaller the TLC, the larger the Pst (L) at full inflation; this observation strongly suggests that volume loss is an important determinant of the change in lung retractive force at high lung volumes. Implicitly this would mean that, in patients with interstitial lung disease, the mechanical properties of the chest wall remain appropriate for a normal volume pair of lungs. Thus, the present data support the view that the chest wall of these patients remains normally compliant and does not stiffen in parallel with the lung volume restriction.

This means that, to compare values of $\mathbf{P ~ p l ~ m i n ~ i n ~}$ patients with interstitial lung disease with those of normal subjects, it is not necessary to correct the predicted normal values for Pst (W). We conclude therefore that the inspiratory muscle strength was, on an average, normal in our patients. On a theoretical basis, it might be suspected that the lung stiffness imposed an increased load and thus, a training effect upon the inspiratory muscles. In these conditions, patients with interstitial lung disease might be expected to develop progressively stronger inspiratory muscles, at least as long as their general nutritional status is well maintained. ${ }^{18}$ It must be noted however that the patients studied here were only moderately disabled.

We thank D Rodenstein who performed the measurements in several healthy adults, and $M$ Douillet for the preparation of the figures. This work was supported in part by grant 7244-00-056 from the Commission of the European Communities (Luxembourg).

\section{References}

1 Druz WS, Danon J, Fishman HC, Goldberg NB, Moisan TC, Sharp JT. Approaches to assessing respiratory muscle function in respiratory disease. Am Rev Respir Dis 1979 (no 2, part 2); 119:145-9.

2 Agostoni E, Mead J. Statics of the respiratory system. In: Fenn WO, Rahn H (ed). Handbook of Physiology: Respiration. Washington DC: American Physiological Society, 1964; 387-409.

3 Rahn H, Otis AB, Chadwick LE, Fenn WO. The pressure-volume diagram of the thorax and lung. Am J Physiol 1946; 146:161-78.

4 Amrein R, Keller R, Joos H, Herzog H. Valeurs théoriques nouvelles de l'exploration de la fonction ventilatoire du poumon. Bull Physiopathol Respir $1970 ; 6: 317-49$.

5 Yernault JC, De Jonghe M, De Coster A, Englert M. Pulmonary mechanics in diffuse fibrosing alveolitis. Bull Physiopathol Respir 1975; 11:231-44.

6 De Troyer A, Yernault JC, Rodenstein D. Influence of beta-2 agonist aerosols on pressure-volume characteristics of the lungs. Am Rev Respir Dis 1978; 118:987-95.

7 De Troyer A, Yernault JC, Englert M, Baran D, Paiva M. Evolution of intrathoracic airway mechanics during lung growth. J Appl Physiol 1978; 44:521-7.

8 Turner JM, Mead J, Wohl ME. Elasticity of human lungs in relation to age. J Appl Physiol 1968; 25:664-71.

9 Gibson GJ, Pride NB, O'Cain C, Quagliato R. Sex and age differences in pulmonary mechanics in normal nonsmoking subjects. J Appl Physiol 1976; 41:20-25.

10 Knudson RJ, Clark DF, Kennedy TC, Knudson DE. Effect of aging alone on mechanical properties of the normal adult human lung. J Appl Physiol 1977; 43:1054-62.

11 Bode FR, Dosman J, Martin RR, Ghezzo H, Macklem PT. Age and sex differences in lung 
elasticity and in closing capacity in nonsmokers. J Appl Physiol 1976; 41:129-35.

12 Yernault JC, De Troyer A, Rodenstein D. Sex and age differences in intrathoracic airway mechanics in normal man. J Appl Physiol 1979; 46:556-64.

13 Ringqvist $T$. The ventilatory capacity in healthy subjects. An analysis of causal factors with special reference to the respiratory forces. Scand J Clin Lab Invest 1966 (suppl 88); 18:1-179.

14 Black LF, Hyatt RE. Maximal respiratory pressures: normal values and relationship to age and sex. Am Rev Respir Dis 1969; 99:696-702.

15 Cook CD, Mead J, Orzalesi MM. Static pressurevolume characteristics of the respiratory system during maximal efforts. J Appl Physiol 1964 19:1016-22.

16 Desmedt JE, Borenstein S. Double-step nerves stimulation test for myasthenic block: sensitization of postactivation exhaustion by ischemia. An Neurol 1977; 1:55-64.

17 Gibson GJ, Pride NB. Pulmonary mechanics in $\overrightarrow{-}$ fibrosing alveolitis. The effects of lung shrinkage:Am Rev Respir Dis 1977; 116:637-47.

18 Rochester DF, Braun NMT, Arora NS. Respiratory? muscle strength in chronic obstructive pulmonary disease. Am Rev Respir Dis 1979 (no 2, part 2) फ् 119:151-4.

\section{Univensity of London, Royal Postgraduate Medical School Practical Applications of Respiratory Physiology}

\section{6-9 May 1980}

This four-day course is intended for those with a strong interest in the assessment of pulmonary function and in its application to clinical problems in general medicine.

Course organisers: Dr J M B Hughes, Dr N B Pride, and Dr M Rudolf.

Course fee: $£ 90$ (including catering).

Application forms and further details may be obtained from: The School Office (SSC), Royal Postgraduate Medical School, Hammersmith Hospital, Du Cane Road, London W12 0HS. Telephone: 01-743 2030, extension 351 